\title{
Myeloid regulatory cells: cross talk of innate and adaptive immunity to maintain the intestinal immune homeostasis in inflammatory bowel disease
}

Jan Däbritz, $\underline{\text { Affl Aff2 }}$

Corresponding Affiliation: Aff1

Toni Weinhage, $\stackrel{\text { Aff1 }}{ }$

Georg Varga,, Affl

Timo Wirth, $\underline{\text { Affl }}$

Jan M Ehrchen,, Affl

Louise M Judd, $\stackrel{\text { Aff2 }}{ }$

Trevelyan R Menheniott, $\stackrel{\text { Aff2 }}{\underline{\text { }}}$

Andrew S Giraud, $\underline{\text { Aff2 }}$

Dirk Foell,, Affl

ArticleInfo

\begin{tabular}{|l|l|l|l||}
\hline \hline ArticleID & $:$ & 44 \\
\hline \hline ArticleDOI & $:$ & $10.1186 / 2194-7791-2-\mathrm{S} 1-\mathrm{A} 4$ \\
\hline \hline ArticleCitationID & $:$ & A4 \\
\hline \hline ArticleSequenceNumber & $:$ & 4 \\
\hline \hline ArticleCategory & $:$ & Meeting abstract \\
\hline \hline ArticleFirstPage & $:$ & 1 \\
\hline \hline ArticleLastPage & $:$ & 2 \\
\hline \hline ArticleHistory & $:$ & $\begin{array}{l}\text { RegistrationDate } \\
\text { OnlineDate }\end{array}$ \\
\hline \hline ArticleCopyright & & $\begin{array}{l}\text { Däbritz et al.2015 } \\
\text { This article is published under license to BioMed Central } \\
\text { Ltd. This is an Open Access article distributed under the } \\
\text { terms of the Creative Commons Attribution License } \\
\text { (http://creativecommons.org/licenses/by/4.0), which permits }\end{array}$ \\
\hline $\begin{array}{l}\text { unrestricted use, distribution, and reproduction in any } \\
\text { medium, provided the original work is properly cited. }\end{array}$
\end{tabular}

Aff1

University Children's Hospital Münster, Münster, NRW, Germany 
Aff2

Murdoch Children's Research Institute, Melbourne, VIC, Australia

Abstracts of the 51st Workshop for Pediatric Research

51st Workshop for Pediatric Research

Göttingen, Germany

16-17 April 2015

This supplement has not been sponsored.

Meeting abstracts

\section{Meeting abstract}

Intestinal monocytes/macrophages sustain the intestinal immune homeostasis and might be an attractive therapeutic target for the management of inflammatory bowel disease (IBD). Granulocyte macrophage colony-stimulating factor (GM-CSF) exerts beneficial effects in intestinal inflammation and promotes STAT3-mediated expansion of myeloid-derived suppressor cells (MDSCs). We explored whether GM-CSF mediates its beneficial effects in IBD via myeloid regulatory cells (Mreg).

Here we show that GM-CSF i) provokes non-classical monocyte activation; ii) drives monocytes towards an anti-inflammatory phenotype; iii) enhances innate immune functions; iv) primes monocyte responses to secondary microbial stimuli; and v) accelerates epithelial healing via monocytes. GM-CSF-activated monocytes (GMaM) show therapeutic activity in T cell-induced colitis in Ragl $^{-/}$mice with increased production of IL-4, IL-10, IL-13 and decreased production of IFN $\gamma$ in LPMCs. Confirming this finding, GMaM attract T cells and shape their differentiation towards Th2 cells in vitro. In addition, GMaM induce regulatory (Foxp $3^{+}$) $\mathrm{T}$ cells (Treg) in vitro and adoptive transfer of GMaM in chronic DSS-induced colitis ameliorates disease in vivo with accelerated gut homing of GMaM and induction of colonic Treg. Myeloid-cell specific STAT3 activation protects gp130 ${ }^{757 \mathrm{~F} / \mathrm{F}}$ mice from colitis via MDSC expansion and increased production of suppressive and protective cytokines. LysMcre/STAT3 ${ }^{\text {flox }}$ mice with myeloid-specific STAT3-deficiency show opposite effects and are not protected from colitis. Additionally, MDSCs of gp130 $0^{757 \mathrm{~F} / \mathrm{F}}$ mice produce significantly more IL-4, IL-10 and IL-13.

In summary, beneficial effects of GM-CSF in IBD may possibly be mediated through reprogramming of monocytes and MDSCs via enhanced innate immune functions as well as regulation of adaptive immunity. Our findings support the exploration of stimulating rather than suppressive therapies for patients with IBD and underpin that Mreg might become a promising novel cell-based therapeutic option. 